\title{
Effect of UV irradiation on thermal properties of nanocomposites based on polylactide
}

\author{
Ewa Olewnik-Kruszkowska
}

Received: 11 March 2014/Accepted: 18 August 2014/Published online: 4 September 2014

(C) The Author(s) 2014. This article is published with open access at Springerlink.com

\begin{abstract}
The aim of the work was to determine the impact of ultraviolet (UV) irradiation on thermal properties of polylactide-based nanocomposites in the form of a film. Polylactide nanocomposites composed of an organoclay (Nanofil2) and with or without a poly( $\varepsilon$-caprolactone) were exposed to UV radiation in air at a wavelength of maximum $254 \mathrm{~nm}$. Thermogravimetric analysis (TG) and differential scanning calorimetry (DSC) were used in order to investigate the thermal properties of samples during the process of photodegradation. Influence of Nanofil2 quantity and the presence of poly( $\varepsilon$-caprolactone) on thermal properties of polylactide-based nanocomposites during UV exposure has been discussed. It has been established that introduction of Nanofil2 as a nanofiller and a compatibilizing agent into polylactide matrix can affect photodegradation of studied materials. The results of DSC analysis indicate that the rate of degradation process was decreased in the presence of modified montmorillonite.
\end{abstract}

Keywords Polylactide - Nanofiller - Photodegradation . Thermal properties

\section{Introduction}

Currently, because of the modern research methods and the development of nanotechnology, novel materials are being obtained- some of them based on biodegradable polymers. It is common knowledge that the presence of small quantity

E. Olewnik-Kruszkowska ( $\square)$

Chair of Physical Chemistry and Physicochemistry of Polymers,

Faculty of Chemistry, Nicolaus Copernicus University, Gagarin

7 street, 87-100 Toruń, Poland

e-mail: olewnik@umk.pl of a nanofiller (3-5\%) significantly increases the elasticity module, thermal stability and improves the barrier properties of the newly obtained composite materials in comparison with the original polymer [1, 2]. The question is how incorporated additives influence the degradation processes of obtained nanocomposites.

The most common degradation processes comprise photo-oxidative and chemical degradation, taking place spontaneously or as a result of adding specific substances to the polymer. Photo-oxidative degradation is the process of decomposition of the material by means of light, which is considered as one of the primary sources of damage to polymeric substrates in ambient conditions [3, 4]. Normally, the near UV radiation (290-400 nm) in the sunlight determines the usability span of polymeric materials in outdoor applications. Photo-oxidative degradation may take place in polymers comprising elements absorbing UV radiation or additives sensitive to radiation [5]. Under UV radiation, the polymer degrades into shorter chains which may continue to degrade photo-oxidatively or decompose when they are affected by chemical or biological factors [6]. The degradation process commences after a certain amount of time has passed, depending on the type and quantity of modifying agents, and involves degradation resulting in a reduction of thermal properties and the deterioration of all physico-chemical properties of the polymer matrix [7].

In spite of generally extensive discussion in the literature devoted to nanocomposite materials, only a few papers deal with the ultraviolet photodegradation. So far these studies concern nanocomposites consisting of montmorillonite (MMT) and classic polymer matrices, such as polypropylene, polyethylene and polycarbonate [8-10].

Published results also suggest that the nanocomposites degrade faster than the neat polymers $[11,12]$. This relative 
susceptibility of nanocomposites to UV light ageing could constitute a major drawback for the outdoor applications. Several hypotheses were suggested in order to explain this instability: adsorption of additives onto the clay, catalytic effect of impurities on the organoclay or the presence of iron ions in the montmorillonite structure as well as the degradation of the alkyl ammonium cations of MMT [13].

Many authors [14-18] have prepared nanocomposites based on polylactide (PLA) and studied several properties including biodegradability. In spite of that, the biodegradability of PLA organoclay nanocomposite has most often been investigated in relation to compost and enzymatic degradation [17, 19-21].

In regard to my research, it is important to emphasise the fact that so far there have been no studies concerning the influence of organoclay and compatibilizing agents on the change in thermal properties of UV-irradiated PLA nanocomposite. For this reason, the aim of this study was to investigate the influence of the introduction of a nanofiller and a compatibilizer into the PLA matrix on thermal properties after the nanocomposites were exposed to UV radiation.

\section{Materials and methods}

\section{Materials}

Polylactide, type 2002D (NatureWorks ${ }^{\circledR}$, USA), with melt

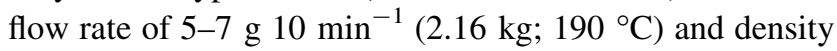
of $1.24 \mathrm{~g} \mathrm{~cm}^{-3}$ was used as the polymer matrix. Nanofil2 (Southern Clay Products, USA) was used as the nanofiller. Poly( $\varepsilon$-caprolactone) CAPA 6506 (Solvay Caprolactones, UK) was used as the compatibilizing agent. Investigated composites were obtained in the same way as described in our previous work [22]. Composition of investigated materials has been presented in Table 1.

Table 1 Compositions of investigated materials (L-polylactide; $\mathrm{N}$ Nanofil2; K-poly(e-caprolactone)) [22]

\begin{tabular}{llcl}
\hline Sample symbol & \multicolumn{3}{l}{ Sample composition (mass parts) } \\
\cline { 2 - 4 } & PLA & $N$ & K \\
\hline L & 100 & - & - \\
LN1 & 100 & 1 & - \\
LN3 & 100 & 3 & - \\
LN5 & 100 & 5 & - \\
LN1K & 100 & 1 & 5 \\
LN3K & 100 & 3 & 5 \\
LN5K & 100 & 5 & 5 \\
LK & 100 & - & 5 \\
\hline
\end{tabular}

Photodegradation conditions

Polylactide-based nanocomposites were exposed to UV radiation using low-pressure mercury vapour lamp TUV30W (Philips, Netherlands) emitting mainly $254 \mathrm{~nm}$ radiation. Exposures took place at room temperature and in air atmosphere. Incident light intensity was $3.12 \mathrm{~mW} \mathrm{~cm}^{-2}$, and the distance between sample and light source was $5 \mathrm{~cm}$. Times of irradiation were $2-16 \mathrm{~h}$.

\section{Characterisations methods}

Thermogravimetric (TG) analyses of PLA and nanocomposites were performed on Simultaneous TGA-DTA Thermal Analysis type SDT 2960 (TA Instruments, UK) All measurements were carried out at a heating rate of $10{ }^{\circ} \mathrm{C} \mathrm{min}{ }^{-1}$ under air flow from room temperature to $600{ }^{\circ} \mathrm{C}$ according to the procedure specified in $\mathrm{PN}$ EN ISO 11358:2004.

Differential scanning calorimetry (DSC) was performed on a differential scanning calorimeter (Polymer Laboratories, Epson, UK) under nitrogen screening. Thermal behaviour of PLA and PLA/clay nanocomposites was examined in a temperature range of $25-220{ }^{\circ} \mathrm{C}$ with a heating rate of $10{ }^{\circ} \mathrm{C} \mathrm{min}^{-1}$ according to $\mathrm{PN}$ EN ISO 11357:2002. The degree of crystallinity $\left(X_{\mathrm{m}}\right)$ was evaluated by applying the following Eq. (1), also used by other authors [2, 23]:

$X_{\mathrm{m}}=\frac{\Delta H_{\mathrm{m}}}{\Delta H^{\mathrm{o}} * X_{\mathrm{PLA}}} * 100 \%$

where $\Delta H_{\mathrm{m}}$ is the measured heat of fusion of sample, $\Delta H^{\mathrm{o}}$ is the heat of fusion of a $100 \%$ crystalline polylactide and $\Delta H^{\mathrm{o}}=109 \mathrm{~J} \mathrm{~g}^{-1}$ [24] and $X_{\mathrm{PLA}}$ is the mass fraction of polylactide.

\section{Results and discussion}

\section{Thermogravimetric analysis}

It is known that the clays have to be modified with a surfactant in order to obtain a hydrophobic nanofiller and large gallery space. The most commonly applied modifying agents are alkyl ammonium salts with long carbon-chains, which determine the thermal stability of nanocomposites. [25].

The presence of the modifying agent can also affect the degradation of nanocomposites and therefore their thermal properties [2]. It is well known that aliphatic, aromatic, cyclic amines and hydroxylamines are used as antioxidants, i.e. substances preventing or delaying oxidation of polymers during degradation. Photo-stabilising properties of amines are derived from the transfer of hydrogen atom 


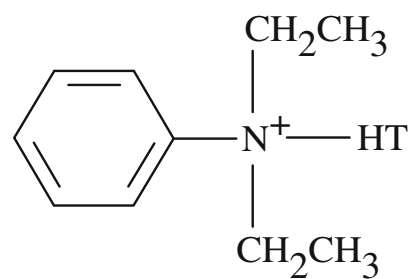

Fig. 1 Scheme of the modifying agent: HT-chains of aliphatic hydrocarbons ( $\left.\sim 65 \% \mathrm{C}_{18} ; \sim 30 \% \mathrm{C}_{16} ; \sim 5 \% \mathrm{C}_{14}\right)$

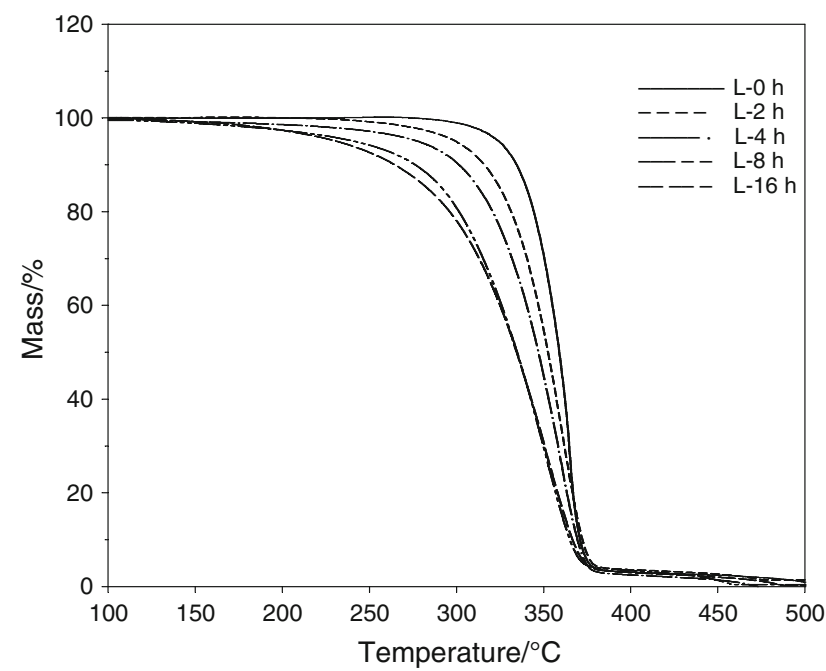

Fig. 2 TG curves of PLA before and after different times of UV exposition

from amine group to free radical. Depending on their structure, amines display differing effectiveness. In the case of aromatic amines, in the first stage of the polymer photostabilization process-in the direct reaction with ROO - an amine radical is formed. In the following stage of the reaction, the amine radical is stabilised by resonance and can react with other radicals forming different types of products [26]. The structure of quaternary amine, which was the modifying agent for Nanofil2, is shown in Fig. 1.

The degradation process is also affected by $\operatorname{poly}(\varepsilon-$ caprolactone) which is used as a compatibilizing agent [27]. Moreover, PCL readily blends with numerous other polymers and is therefore introduced as a plasticiser, changing polymer elasticity and biodegradability.

The aim of the study was to determine the impact the nanofiller-Nanofil2 - and the compatibilizing agent have got on thermal stability of the nanocomposites based on polylactide during photodegradation. The degradation temperatures at 10 and $50 \%$ mass $\operatorname{loss}\left(T_{10} \%\right.$ and $\left.T_{50} \%\right)$ after various periods of photodegradation were selected as reference indexes. An additional parameter $(\Delta T)$,

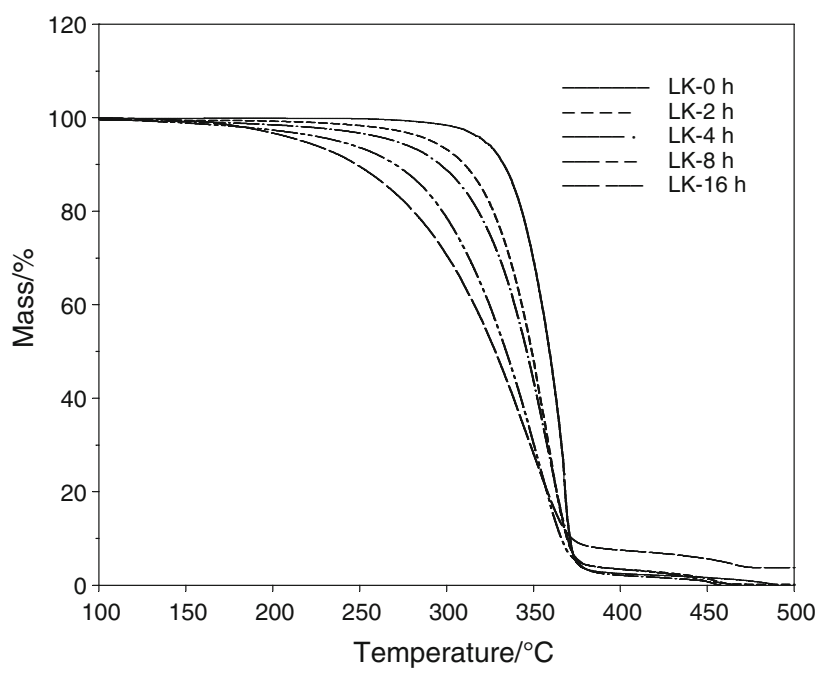

Fig. 3 TG curves of LK sample before and after different times of UV irradiation

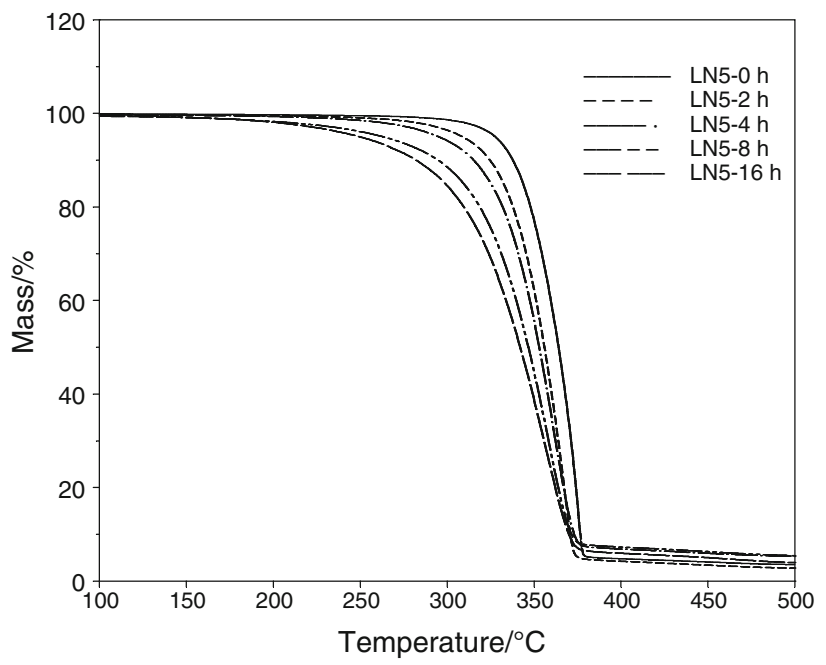

Fig. 4 TG curves of LN5 sample before and after different times of photodegradation

describing the influence of the modified filler and poly( $\varepsilon$ caprolactone) on thermal decomposition of materials, was determined. It was calculated as the difference in $T_{10} \%$ and $T_{50} \%$ values for the initial samples and the samples after $16 \mathrm{~h}$ of exposure to UV radiation. TG curves of polylactide samples, polylactide with 5 mass $\%$ of poly $(\varepsilon$ caprolactone) samples and selected composites before and after $2,4,8$ and $16 \mathrm{~h}$ of UV irradiation are presented in Figs. 2-5.

Polylactide TG curves (Fig. 2) indicate a reduction of sample decomposition temperatures along with the increase in photodegradation time. Before exposure to UV 


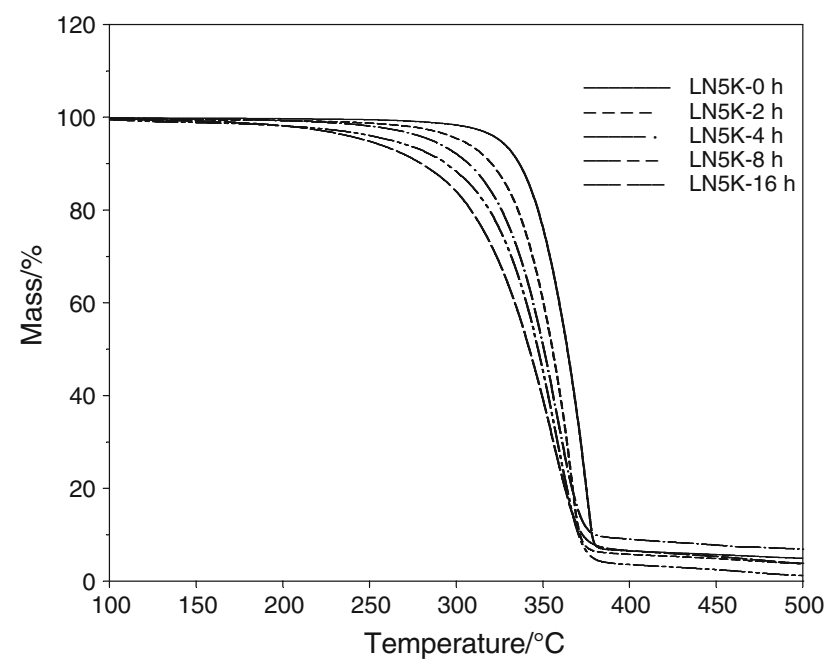

Fig. 5 TG curves of LN5K sample before and after different times UV exposure

Table 2 TG data for PLA and LK samples before and after degradation process

\begin{tabular}{lrrrrr}
\hline Time of irradiation $/ \mathrm{h}$ & \multicolumn{5}{l}{ Temperature $/{ }^{\circ} \mathrm{C}$ at mass loss } \\
\cline { 2 - 3 } & \multicolumn{2}{l}{ PLA } & & LK & \\
\cline { 2 - 3 } \cline { 5 - 6 } & $T_{10 \%}$ & $T_{50 \%}$ & & $T_{10} \%$ & $T_{50 \%}$ \\
\hline 0 & 334.4 & 358.7 & & 332.6 & 358.9 \\
2 & 315.9 & 352.3 & 310.4 & 348.8 \\
4 & 300.9 & 346.7 & 295.9 & 345.8 \\
8 & 276.0 & 334.3 & 269.9 & 333.8 \\
16 & 264.8 & 334.4 & 248.4 & 327.9 \\
$\Delta T$ & 69.6 & 24.3 & 84.2 & 31.0 \\
\hline
\end{tabular}

radiation, the decomposition temperature of the PLA sample at $10 \%$ mass loss equalled $334.4{ }^{\circ} \mathrm{C}$ and decreased to $260.8{ }^{\circ} \mathrm{C}$ after $16 \mathrm{~h}$ of irradiation. At $50 \%$ mass loss, the difference in temperatures between the initial PLA sample and the sample irradiated for $16 \mathrm{~h}$ equalled $29.4{ }^{\circ} \mathrm{C}$. Temperatures in the case of polylactide and polylactide with a PCL addition, before and after different periods of irradiation $(2,4,8,16 \mathrm{~h})$, at 10 and $50 \%$ mass loss in the function of temperature as well as the temperature difference between the initial sample and the sample after $16 \mathrm{~h}$ of exposure $(\Delta T)$ have been depicted in Table 2 . After introducing poly ( $\varepsilon$-caprolactone) into polylactide, the stability of LK sample was reduced along with the increase in UV exposure time (Fig. 3). LK decomposition temperature value (Table 2) at $10 \%$ mass loss decreased from $332.6{ }^{\circ} \mathrm{C}$ at $0 \mathrm{~h}$ to $248.4{ }^{\circ} \mathrm{C}$ at $16 \mathrm{~h}$ of irradiation, amounting to a difference of $84.2{ }^{\circ} \mathrm{C}$. The temperature at
Table 3 TG data for LN1, LN3 and LN5 nanocomposites before and after photodegradation

\begin{tabular}{|c|c|c|c|c|c|c|}
\hline \multirow[t]{3}{*}{ Time of irradiation $/ \mathrm{h}$} & \multicolumn{6}{|c|}{ Temperature $/{ }^{\circ} \mathrm{C}$ at mass loss } \\
\hline & \multicolumn{2}{|l|}{ LN1 } & \multicolumn{2}{|l|}{ LN3 } & \multicolumn{2}{|l|}{ LN5 } \\
\hline & $T_{10 \%}$ & $T_{50} \%$ & $T_{10 \%}$ & $T_{50 \%}$ & $T_{10 \%}$ & $T_{50 \%}$ \\
\hline 0 & 330.6 & 357.2 & 336.5 & 360.1 & 337.7 & 363.8 \\
\hline 2 & 312.7 & 349.1 & 320.7 & 352.9 & 324.4 & 355.6 \\
\hline 4 & 298.2 & 345.0 & 308.0 & 349.1 & 315.2 & 352.7 \\
\hline 8 & 282.5 & 340.9 & 293.8 & 345.2 & 295.0 & 346.5 \\
\hline 16 & 258.5 & 328.0 & 270.9 & 336.4 & 281.9 & 341.7 \\
\hline$\Delta T$ & 72.1 & 29.2 & 65.6 & 23.7 & 55.9 & 22. \\
\hline
\end{tabular}

$50 \%$ mass loss decreased from $358.9^{\circ} \mathrm{C}$ at $0 \mathrm{~h}$ to $327.9^{\circ} \mathrm{C}$ at $16 \mathrm{~h}$ of UV exposure, resulting in $\Delta T$ equal to $31^{\circ} \mathrm{C}$. It needs to be stressed that the thermal stability after adding $5 \%$ of PCL to PLA decreased in comparison with neat polylactide in the case of both initial and irradiated samples. This suggests that the photodegradation of polylactide comprising $5 \%$ of poly( $\varepsilon$-caprolactone) occurs more rapidly than the degradation of neat polylactide [28].

Thermogravimetric analysis was also applied to polylactide samples with an addition of 1,3 and $5 \%$ montmorillonite modified with an organic fraction (named LN1, LN3 and LN5, respectively). In the case of all materials consisting of PLA and Nanofil2, a shift in thermogravimetric curves, after varying times of irradiation, towards higher temperatures, in comparison with polylactide TG curves, can be observed. The thermogravimetric curves of LN5 sample after varying times of UV exposure are an example of such phenomenon (Fig. 4). It is noteworthy that thermostability of nanocomposites after photodegradation increases along with the increase in the nanofiller load, indicated by the reduced $\Delta T$ value (Table 3 ).

It can be deduced that the above-mentioned phenomenon is related to the presence of amine cation in the interlayer spaces of montmorillonite. The cations are responsible for increasing the distance between the layers of nano-clay and transform the hydrophilic properties of the filler to hydrophobic. As a result, it allows the layers of montmorillonite to be more easily penetrated by the polymer and facilitates the formation of exfoliated structures which constitute a barrier for the gas products of sample degradation.

Thermal stability after photodegradation of materials containing polylactide, acting as a polymer matrix, Nanofil2 as a nanofiller and poly( $\varepsilon$-caprolactone), acting as a compatibilizing agent, can be analysed in reference to neat polylactide, polylactide comprising $5 \%$ PCL as well as PLA-Nanofil2 configurations. 
Table 4 TG data for LN1K, LN3K and LN5K nanocomposites before and after UV irradiation

\begin{tabular}{|c|c|c|c|c|c|c|}
\hline \multirow[t]{3}{*}{ Time of irradiation $/ \mathrm{h}$} & \multicolumn{6}{|c|}{ Temperature $/{ }^{\circ} \mathrm{C}$ at mass loss } \\
\hline & \multicolumn{2}{|l|}{ LN1K } & \multicolumn{2}{|l|}{ LN3K } & \multicolumn{2}{|l|}{ LN5K } \\
\hline & $T_{10} \%$ & $T_{50} \%$ & $T_{10} \%$ & $T_{50} \%$ & $T_{10} \%$ & $T_{50} \%$ \\
\hline 0 & 333.5 & 357.3 & 335.8 & 362.1 & 336.4 & 363.9 \\
\hline 2 & 312.5 & 351.4 & 316.4 & 352.5 & 320.4 & 355.3 \\
\hline 4 & 302.6 & 348.3 & 303.8 & 348.4 & 307.2 & 350.4 \\
\hline 8 & 285.4 & 342.7 & 285.0 & 344.1 & 283.9 & 346.9 \\
\hline 16 & 260.0 & 331.6 & 266.0 & 334.8 & 279.6 & 341.9 \\
\hline$\Delta T$ & 73.5 & 25.7 & 69.8 & 27.3 & 56.8 & 22.0 \\
\hline
\end{tabular}

When compared to neat polylactide and LK samples, the photodegradation of three-component structures occurs less dynamically, as indicated by the following $\Delta T$ values (Table 4).

Comparing the temperature change in $T_{10} \%$ and $T_{50} \%$ before and after photodegradation in the case of polylactide-Nanofil 2 materials and LN samples with an addition of compatibilizing agent, an increase in $\Delta T$ values can be observed. Therefore, it is justified to assume that the presence of PCL accelerated the photodegradation of PLANanofil2 structures. Examples of thermogravimetric curves in the case of the three-component structures before and after different times of photodegradation have been depicted in Fig. 5.

When discussing the above-mentioned results, obtained in the case of materials containing poly( $\varepsilon$-caprolactone), it must be taken into account that TG curves do not allow a distinction between the PLA and PCL mass loss. Therefore, unlike the DSC method, when applying the TG method only degradation of all LNK materials can be inspected, not the degradation of individual polymers (PLA and PCL).

The thermogravimetric analysis indicated that the presence of montmorillonite modified with quaternary amine delays the photodegradation process of polylactide, whereas the presence of poly( $\varepsilon$-caprolactone) accelerates the decomposition of investigated materials occurring during exposure to UV radiation.

Differential scanning calorimetry analyses

In order to determine the thermal properties of the studied samples during photodegradation, apart from thermogravimetric, differential scanning calorimetry method was also applied. DSC curves of initial samples were noted, as well as curves after varied times of irradiation $(2,4,8$, $16 \mathrm{~h})$. The DSC curves were the basis for determining such parameters as glass transition temperature $\left(T_{\mathrm{g}}\right)$, crystallisation temperature $\left(T_{\mathrm{c}}\right)$, heat of crystallisation $\left(\Delta H_{\mathrm{c}}\right)$,

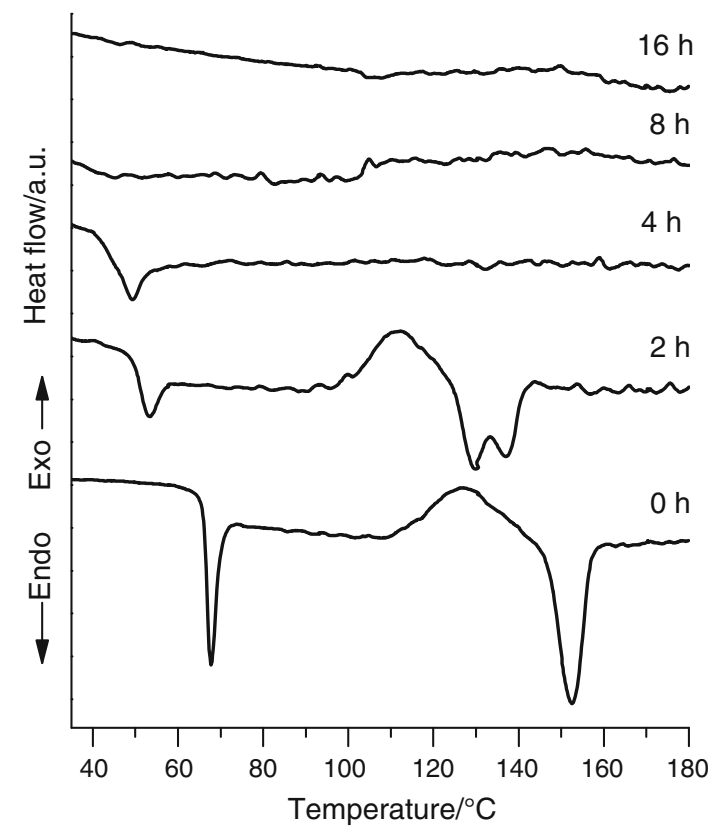

Fig. 6 DSC curves PLA before and after UV exposition

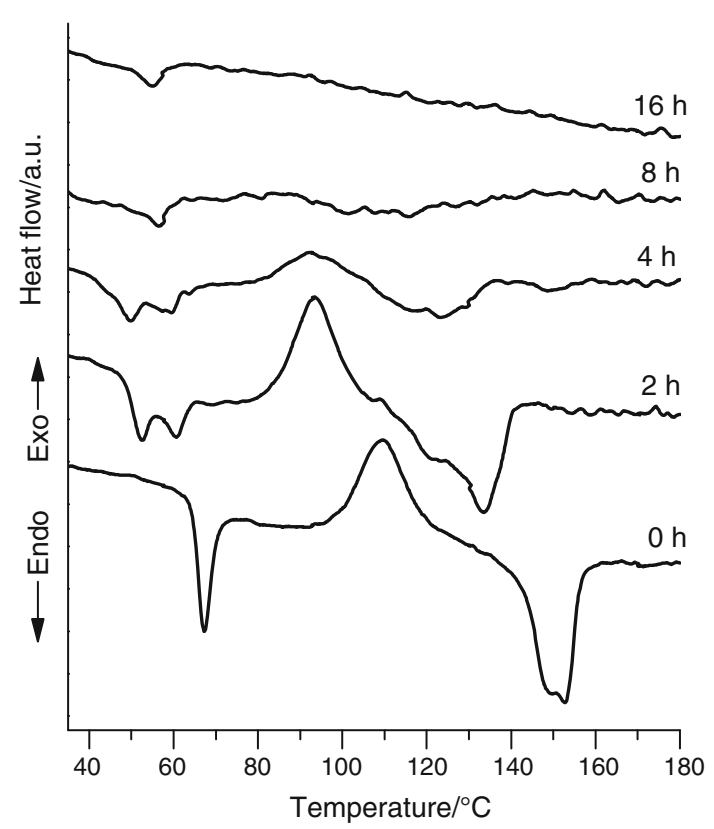

Fig. 7 DSC curves of LK before and after different times of photodegradation

melting temperature $\left(T_{\mathrm{m}}\right)$, heat of fusion $\left(\Delta H_{\mathrm{m}}\right)$ and degree of crystallinity $\left(X_{\mathrm{c}}\right)$.

Figures 6 and 7 depict the impact the UV radiation has got on the thermal properties of polylactide and the PLA sample with an addition of poly( $\varepsilon$-caprolactone). Exact values of parameters derived from polylactide and LK DSC 
Table 5 DSC parameters of polylactide and nanocomposites LN1, LN3, LN5 before and after a different periods of exposition to UV irradiation

\begin{tabular}{|c|c|c|c|c|c|c|}
\hline Sample & $T_{\mathrm{g}}^{\mathrm{PLA} /{ }^{\circ} \mathrm{C}}$ & $T_{\mathrm{c}}^{\mathrm{PLA} /{ }^{\circ} \mathrm{C}}$ & $\Delta H_{\mathrm{c}}^{\mathrm{PLA}} / \mathrm{J} \mathrm{g}^{-1}$ & $T_{\mathrm{m}}^{\mathrm{PLA} /{ }^{\circ} \mathrm{C}}$ & $\Delta H_{\mathrm{m}}^{\mathrm{PLA}} / \mathrm{J} \mathrm{g}^{-1}$ & $X_{\mathrm{c}}^{\mathrm{PLA} / \%}$ \\
\hline $\mathrm{L}-0 \mathrm{~h}$ & 66.6 & 127.1 & -14.4 & 152.5 & 16.5 & 15.1 \\
\hline L-2 h & 51.0 & 112.3 & -13.8 & $129.80 / 137.0$ & 15.0 & 13.8 \\
\hline L-4 h & 45.1 & - & - & - & - & - \\
\hline $\mathrm{L}-8 \mathrm{~h}$ & - & - & - & - & - & - \\
\hline $\mathrm{L}-16 \mathrm{~h}$ & - & - & - & - & - & - \\
\hline LN1-0 h & 66.1 & 123.3 & -10.6 & 152.2 & 16.7 & 15.5 \\
\hline LN1-2 h & 51.0 & 113.9 & -13.2 & $133.6 / 138.9$ & 15.7 & 14.5 \\
\hline LN1-4 h & 45.7 & - & - & - & - & - \\
\hline LN1-8 h & - & - & - & - & - & - \\
\hline LN1-16 h & - & - & - & - & - & - \\
\hline LN3-0 h & 65.7 & 123.4 & -9.3 & 152.8 & 15.9 & 15.0 \\
\hline LN3-2 h & 52.5 & 114.5 & -22.3 & $139.4 / 144.7$ & 26.7 & 25.3 \\
\hline LN3-4 h & 52.0 & 116.5 & -7.5 & $132.7 / 136.5$ & 8.2 & 7.8 \\
\hline LN3-8 h & 46.2 & - & - & - & - & - \\
\hline LN3-16 h & 41.6 & - & - & - & - & - \\
\hline LN5-0 h & 66.0 & 125.2 & -8.2 & 153.5 & 12.6 & 12.2 \\
\hline LN5-2 h & 52.8 & 118.3 & -17.9 & $144.9 / 149.4$ & 24.9 & 24.0 \\
\hline LN5-4 h & 52.1 & 118.0 & -7.1 & $138.3 / 142.4$ & 12.4 & 12.0 \\
\hline LN5-8 h & 50.4 & 113.8 & -1.5 & $128.5 / 132.3$ & 3.3 & 3.2 \\
\hline LN5-16 h & 43.9 & - & - & - & - & - \\
\hline
\end{tabular}

curves have been presented in Tables 5 and 6 . Analysis of the above-mentioned data indicates that the $T_{\mathrm{g}}, T_{\mathrm{c}}^{\mathrm{PLA}}$, $\Delta H_{\mathrm{c}}^{\mathrm{PLA}}, T_{\mathrm{m}}^{\mathrm{PLA}}, \Delta H_{\mathrm{m}}^{\mathrm{PLA}}, X_{\mathrm{c}}^{\mathrm{PLA}}$ —as well as $T_{\mathrm{m}}^{\mathrm{PCL}}$ and $\Delta H_{\mathrm{m}}^{\mathrm{PCL}}$ in the case of LK sample-decrease along with the increase in the UV exposure time of polylactide and LK samples.

Glass transition temperature depends on the structure of the polymer chain, its elasticity and the molecular mass of the polymer. During photodegradation, the main polymer chain is severed, reducing the molecular mass of the polymer, resulting in the reduction of the $T_{\mathrm{g}}$ value in the case of both researched materials - L and LK samples- to a similar extent. During the crystallisation process, the $T_{\mathrm{c}}^{\text {PLA }}$ values are much lower in the case of the LK sample than the values corresponding with the polylactide sample at all times of UV irradiation. In relation to $\Delta H_{\mathrm{c}}^{\mathrm{PLA}}$ of the $\mathrm{L}$ and LK samples, the polylactide sample with an addition of poly( $\varepsilon$-caprolactone) is characterised by higher heat of crystallisation. Moreover, the crystallisation peak can be observed also after $4 \mathrm{~h}$ of LK irradiation, whereas in the case of neat polylactide the cold crystallisation peak fades entirely. This phenomenon suggests that the presence of poly( $\varepsilon$-caprolactone) results in the increase of the crystalline phase ratio in the sample during heating. It is known that the heat of crystallisation $\left(\Delta H_{\mathrm{c}}\right)$ is proportional to the surface under the exotherm of crystallisation and depends on both mass of crystalline phase that is formed while the melted sample is being cooled, as well as the quality of this phase [29]. It is noteworthy that after adding poly( $\varepsilon$-caprolactone) to polylactide, a significant increase of heat of fusion and degree of crystallinity can be observed in comparison to neat polylactide, which confirms the hypothesis that PCL is the nucleus of crystallisation.

Melting of polymers occurs in a certain temperature range and depends on the degree of crystallinity, size and quality of crystallite, arrangement of macromolecules and molecular mass of the polymer [30]. In the DSC curve of the polylactide sample after $2 \mathrm{~h}$ of irradiation, two melting temperatures can be observed. This phenomenon can be explained by a bimodal process of melting which is typical of bimodal polymers [31]. A bimodal polymer consists of two fractions of a different molecular mass. Two combinable factions of a bimodal form a compatible blend, as indicated by a single peak in the initial polylactide sample $[32,33]$. Bimodal polymers possess far superior mechanical and processing properties. After UV exposure, a delamination of the two bimodal polymer fractions occurs, and as a result the polylactide DSC curve after $2 \mathrm{~h}$ of irradiation shows two melt temperatures (Fig. 6). The dominant effect of one of the $T_{\mathrm{m}}$ is responsible for a different thermal stability of the crystallites formed in the samples characterised by different compositions and therefore by a different ageing history. 
Table 6 DSC parameters of LK sample and nanocomposites LN1K, LN3K, LN5K before and after a different periods of exposition to UV irradiation

\begin{tabular}{|c|c|c|c|c|c|c|c|c|}
\hline Sample & $T_{\mathrm{g}}^{\mathrm{PLA} A} /{ }^{\circ} \mathrm{C}$ & $T_{\mathrm{c}}^{\mathrm{PLA}} /{ }^{\circ} \mathrm{C}$ & $\Delta H_{\mathrm{c}}^{\mathrm{PLA}} / \mathrm{J} \mathrm{g}^{-1}$ & $T_{\mathrm{m}}^{\mathrm{PLA} /{ }^{\circ} \mathrm{C}}$ & $\Delta H_{\mathrm{m}}^{\mathrm{PLA}} / \mathrm{J} \mathrm{g}^{-1}$ & $T_{\mathrm{m}}^{\mathrm{PCL} /{ }^{\circ} \mathrm{C}}$ & $\Delta H_{\mathrm{m}}^{\mathrm{PCL}} / \mathrm{J} \mathrm{g}^{-1}$ & $X_{\mathrm{c}}^{\mathrm{PLA}} / \%$ \\
\hline LK-0 h & 65.7 & 109.6 & -15.0 & $149.0 / 152.8$ & 22.8 & - & - & 22.0 \\
\hline LK-2 h & 50.2 & 93.4 & -19.9 & $121.5 / 133.6$ & 27.2 & 60.7 & 1.7 & 26.3 \\
\hline LK-4 h & 47.2 & 92.6 & -6.7 & $117.8 / 123.1$ & 12.3 & 57.3 & 1.4 & 11.9 \\
\hline LK-8 h & - & - & - & - & - & 56.5 & 3.8 & - \\
\hline LK-16 h & - & - & - & - & - & 55.3 & 1.3 & - \\
\hline LN1K-0 h & 65.9 & 109.4 & -14.9 & $148.0 / 153.6$ & 23.0 & - & - & 22.4 \\
\hline LN1K-2 h & 51.7 & 95.2 & -22.5 & $128.7 / 138.6$ & 30.4 & 60.4 & 1.3 & 29.7 \\
\hline LN1K-4 h & 48.2 & 86.2 & -11.5 & $119.7 / 124.5$ & 22.2 & 59.2 & 1.3 & 21.7 \\
\hline LN1K-8 h & 34.1 & 76.5 & -2.0 & $101.6 / 113.8$ & 7.7 & 56.8 & 1.1 & 7.5 \\
\hline LN1K-16 h & - & - & - & - & - & 55.6 & 1.4 & - \\
\hline LN3K-0 h & 65.3 & 106.1 & -13.0 & $147.8 / 152.6$ & 20.1 & - & - & 20.0 \\
\hline LN3K-2 h & 50.5 & 93.9 & -16.8 & $116.0 / 121.2 / 132.5$ & 27.9 & 60.6 & 1.5 & 27.8 \\
\hline LN3K-4 h & 51.1 & 88.8 & -12.1 & $123.1 / 131.2$ & 17.76 & 60.3 & 1.2 & 17.7 \\
\hline LN3K-8 h & 44.2 & 83.3 & -3.0 & 111.0/118.9/122.1 & 8.6 & 59.4 & 0.9 & 8.6 \\
\hline LN3K-16 h & - & - & - & - & - & 56.6 & 1.4 & - \\
\hline LN5K-0 h & 65.2 & 108.0 & -22.0 & $148.1 / 153.4$ & 30.3 & - & - & 30.9 \\
\hline LN5K-2 h & 52.3 & 98.4 & -17.6 & $136.8 / 141.7$ & 26.1 & 60.7 & 0.7 & 26.6 \\
\hline LN5K-4 h & 53.4 & 93.3 & -12.5 & $127.8 / 132.4 / 136.6$ & 16.7 & - & - & 17.0 \\
\hline LN5K-8 h & 45.3 & 85.9 & 4.9 & $108.41 / 116.21 / 122.6$ & 12.4 & 58.9 & 0.6 & 12.6 \\
\hline LN5K-16 h & 36.9 & 96.0 & 2.9 & $122.69 / 126.07 / 133.0$ & 4.2 & 59.7 & 1.3 & 4.3 \\
\hline
\end{tabular}

In the DSC curve of LK sample after $2 \mathrm{~h}$ of irradiation (Fig. 7), a new parameter is visible-melting temperature of poly ( $\varepsilon$-caprolactone) $\left(T_{\mathrm{m}}^{\mathrm{PCL}}\right)$ of $60.7^{\circ} \mathrm{C}$. Melting temperature of poly ( $\varepsilon$-caprolactone) in the case of non-exposed LK sample overlaps the glass transition temperature of polylactide. As a result of UV exposure, the PCL melt temperature falls to $55.3{ }^{\circ} \mathrm{C}$ after $16 \mathrm{~h}$ of irradiation. Based on the data in Table 6 and Fig. 7, it has been determined that the melting process of poly( $\varepsilon$-caprolactone) can only be observed after 8 and $16 \mathrm{~h}$ of UV exposure of the LK sample.

While discussing the photodegradation of polylactide and polylactide with an addition of PCL it can generally be noted that after $4 \mathrm{~h}$ of UV exposure, in the case of polylactide, only the glass transition temperature can be observed. Conversely, in the case of LK sample, all transitions typical of polylactide as well as poly( $\varepsilon$-caprolactone) have been noted.

Table 5 depicts DSC parameters of both initial LN1, LN3 and LN5 composites as well as of samples after different times of UV exposure. In the case of LN1 and neat polylactide after $4 \mathrm{~h}$ of degradation, only glass transition temperature can be observed. Conversely, the DSC curves of the LN3 sample after $4 \mathrm{~h}$ of irradiation and the LN5 sample after $8 \mathrm{~h}$ of irradiation (Fig. 8) still show three transitions: glass, crystallisation and melting. During photodegradation, in the case of all samples, a shift in temperatures of all transitions towards lower values has been noted.

Initial glass transition temperatures of polylactide filled with montmorillonite modified by an organic fraction (N) are slightly lower than $T_{\mathrm{g}}$ of neat polylactide. During photodegradation, the $T_{\mathrm{g}}$ temperature falls at a much slower rate with the increase of the filler content in the composites. The decrease of $T_{\mathrm{g}}$ can be explained by the formation of the low-molecular mass products which plasticise PLA and change macromolecular order [34]. It needs to be emphasised that for polylactide and sample containing $1 \%$ of Nanofil2, the glass transition temperature after $4 \mathrm{~h}$ of UV irradiation is no longer noticeable, while in the case of samples containing 3 and 5 mass $\%$ of nanofiller, $T_{\mathrm{g}}$ of PLA can still be observed even after $16 \mathrm{~h}$ of UV exposure. This suggests that MMT modified with quaternary ammonium salt can delay photodegradation process.

A decrease in crystallisation temperature values for $\mathrm{LN}$ samples has also been noted. The crystallisation is not visible after $16 \mathrm{~h}$ of $\mathrm{UV}$ irradiation but it prevails longer during photodegradation along with the increase in quantity of the filler in polymer matrix. Cold crystallisation temperature changes have been noted as follows: from $123.3{ }^{\circ} \mathrm{C}$ to $113.9{ }^{\circ} \mathrm{C}$ after $2 \mathrm{~h}$ of exposure in the case of LN1 sample, from $123.4{ }^{\circ} \mathrm{C}$ to $116.5^{\circ} \mathrm{C}$ after $4 \mathrm{~h}$ in 


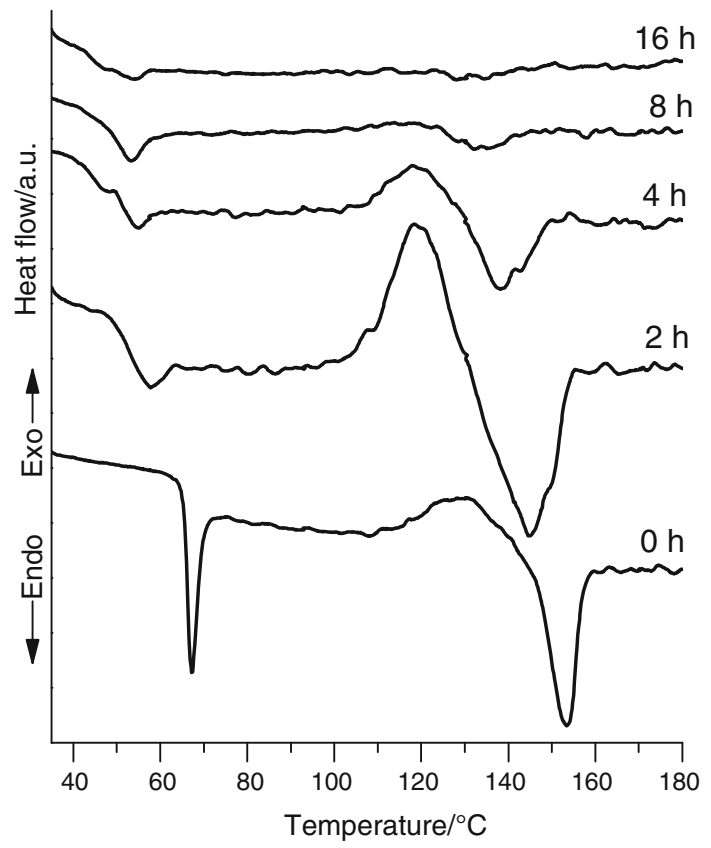

Fig. 8 DSC curves of LN5 before and after different times of exposition to UV

relation to LN3 sample and from $125.2{ }^{\circ} \mathrm{C}$ to $113.8{ }^{\circ} \mathrm{C}$ after $8 \mathrm{~h}$ of exposure of LN5 sample (Table 5). In view of the above-mentioned results the impact the quantity of the filler, and consequently the quantity of the modifying agent, has got on the degradation of polylactide is apparent.

In the case of LN1, LN3 and LN5 composite samples as well as polylactide, only one melting point is observed before the UV irradiation. Bimodal melting process occurs in all samples after $2 \mathrm{~h}$ of photodegradation and can still be observed after $4 \mathrm{~h}$ in the case of LN3 and after $8 \mathrm{~h}$ in the case of LN5 sample. This indicates that with the increase in filler content, the bimodal melting still occurs after extended periods of irradiation. Despite Nanofil2 not being the crystal nucleus, a slower decomposition of crystalline phase can be observed, resulting from the stabilising effect the modifying agent has got during the photodegradation of LN materials.

The DSC analysis was also applied to samples before and after varied time of UV exposure comprising polylactide, $5 \%$ poly( $\varepsilon$-caprolactone) and Nanofil 2 from 1 to $5 \%$. The DSC results for LK sample, the LN1K, LN3K and LN5K composites before and after different times of irradiation have been presented in Table 6 .

The glass transition temperature of LK sample is visible only after $4 \mathrm{~h}$ of UV irradiation, for LN1K and LN3K samples, it can be observed after $8 \mathrm{~h}$ of UV exposure while for LN5K sample it can be noted after as much as $16 \mathrm{~h}$ of UV exposition. In the case of LN1K sample, $T_{\mathrm{g}}$ a decrease from an initial value of $65.9{ }^{\circ} \mathrm{C}$ to $34.1{ }^{\circ} \mathrm{C}$ occurred after

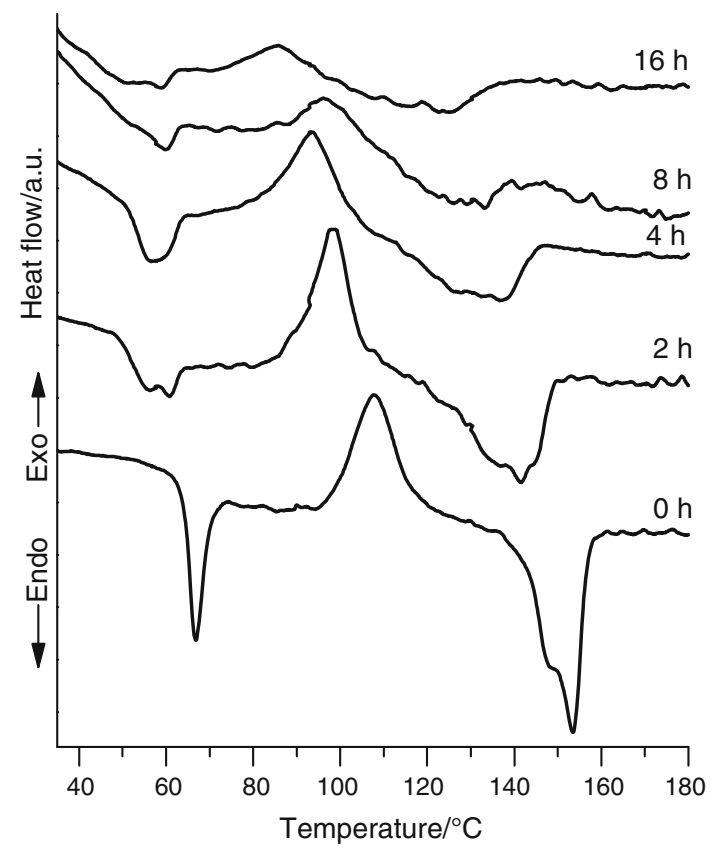

Fig. 9 DSC curves of LN5K before and after different times of photodegradation

$8 \mathrm{~h}$ of irradiation. Before UV exposure, the glass transition temperature of LN3K sample equalled $65.3{ }^{\circ} \mathrm{C}$ and after $8 \mathrm{~h}$ of photodegradation fell to $44.2{ }^{\circ} \mathrm{C}$. In relation to LN5K sample, the initial $T_{\mathrm{g}}$ amounted to $65.2^{\circ} \mathrm{C}$ and decreased gradually to $45.5{ }^{\circ} \mathrm{C}$ after $8 \mathrm{~h}$ of irradiation to reach $36.9^{\circ} \mathrm{C}$ after a total of $16 \mathrm{~h}$ of UV exposure. The above-mentioned results indicate that the quantity of filler has got a significant impact on the photodegradation of polylactide.

While the time of exposure increases, the values of crystallisation and melting temperatures of LN1K, LN3K and LN5K decrease. Similarly, as in the case of $T_{\mathrm{g}}$, the reduction in $T_{\mathrm{c}}^{\text {PLA }}$ and $T_{\mathrm{m}}^{\text {PLA }}$ occurs less dynamically when the quantity of filler increases. According to the results presented in Table 6, two PLA melt temperatures have been noted in relation to all material comprising PCL and Nanofil2. It needs to be emphasised that an exceptionally high melt enthalpy of tri-compound structures has been noted as well as the degree of crystallinity which again indicates that poly( $\varepsilon$-caprolactone) acts as nucleus of crystallinity.

In the case of LN1K and LN3K samples after $8 \mathrm{~h}$ of UV exposure, three transitions can be observed: glass, crystallisation and melt transition. In relation to LN5K sample, all parameters are present throughout the entire UV exposition (Fig. 9). It is due to the improved dispersion of the filler in the polymer matrix resulting from the presence of the compatibilizing agent. As a result, polylactide photodegradation occurs more slowly within the whole sample 
volume. Moreover, poly( $\varepsilon$-caprolactone) allows the shortened polymer chains to reorganise during the photodegradation process.

\section{Conclusions}

Based on TG and DSC analyses applied before and after different times of photodegradation, it has been concluded that

- Introducing modified montmorillonite into polylactide causes the TG curves-both the initial and the ones obtained after different times of exposure-to shift towards higher temperatures in comparison with neat polylactide. It is due to the presence of quaternary amine in the interlayer spaces of the filler which acts as a stabilising agent in the photodegradation process.

- Thermal stability of polylactide filled with Nanofil2 raises with the increase in quantity of the added filler, as indicated by the TG and DSC methods.

- Addition of the compatibilizing agent into the polylactide/modified montmorillonite system, as well as into neat polylactide, reduced $T_{10} \%$ and $T_{50} \%$ mass loss temperatures; however, it did not allow to establish whether the mass loss noted in the TG curves is related to polylactide or to both polymers, since the degradation occurs at the same stage.

Acknowledgements This research project has been supported by the National Centre of Science, Contract No. DEC-2011/03/D/ST8/ 04126 .

Open Access This article is distributed under the terms of the Creative Commons Attribution License which permits any use, distribution, and reproduction in any medium, provided the original author(s) and the source are credited.

\section{References}

1. Leszczynska A, Pielichowski K. Application of thermal analysis methods for characterization of polymer/montmorillonite nanocomposites. J Therm Anal Calorim. 2008;93:677-87.

2. Chow WS, Lok SK. Thermal properties of poly(lactic acid)/ organo-montmorillonite nanocomposites. J Therm Anal Calorim. 2009;95:627-32.

3. Zaidi L, Kaci M, Bruzaud S, Bourmaud A, Grohens Y. Effect of natural weather on the structure and properties of polylactide/cloisite 30B nanocomposites. Polym Degrad Stab. 2010;95:1751-8.

4. Kumanayaka TO, Parthasarathy R, Jollands M. Accelerating effect of montmorillonite on oxidative degradation of polyethylene nanocomposites. Polym Degrad Stab. 2010;95:672-6.

5. Diagne M, Gueye M, Dasilva A, Vidal L, Tidjani A. The effect of photo-oxidation on thermal and fire retardancy of polypropylene nanocomposites. J Mater Sci. 2006;41:7005-10.
6. Bocchini S, Fukushima K, Di Blasio A, Fina A, Frache A, Geobaldo F. Polylactic acid and polylactic acid-based nanocomposite photooxidation. Biomacromolecules. 2010;11:2919-26.

7. Botta L, Dintcheva NT, La Mantia FP. The role of organoclay and matrix type in photo-oxidation of polyolefin/clay nanocomposite films. Polym Degrad Stab. 2009;94:712-8.

8. Kumar AP, Depan D, Tomer NS, Singh RP. Nanoscale particles for polymer degradation and stabilization-trends and future perspectives. Prog Polym Sci. 2009;34:479-515.

9. Belbachir S, Zairi F, Ayoub G, Maschke U, Nait-Abdelaziz M, Gloaguen JM. Modelling of photodegradation effect on elasticviscoplastic behaviour of amorphous polylactic acid films. J Mech Phys Solids. 2010;58:241-55.

10. Morlat-Therias S, Fanton E, Gardette JL, Peeterbroeck P, Alexandre M, Dubois P. Polymer/carbon nanotube nanocomposites: influence of carbon nanotubes on EVA photodegradation. Polym Degrad Stab. 2007;93:1873-82.

11. Leroux F, Meddar L, Mailhot B, Morlat-Therias S, Gardette JL. Characterization and photooxidative behaviour of nanocomposites formed with polystyrene and LDHs organo-modified by monomer surfactant. Polymer. 2005;46:3571-8.

12. Morlat S, Mailhot B, Gonzalez D. Gardette JL; Photo-oxidation of polypropylene/montmorillonite nanocomposites. 1. Influence of nanoclay and compatibilizing agent. Chem Mater. 2004;16:377-81.

13. Morlat-Therias S, Mailhot B, Gonzalez D, Gardette JL. Photooxidation of Polypropylene/Montmorillonite Nanocomposites. 2. Interactions with Antioxidants. Chem Mater. 2005;17:1072-80.

14. Ray SS, Okamoto M. Polymer/layered silicate nanocomposites: a review from preparation to processing. Prog Polym Sci. 2003;11:1539-83.

15. Ray SS, Maiti P, Okamoto M, Yamada K, Ueda K. New polylactide/layered silicate nanocomposites. 1. preparation, characterization and properties. Macromolecules. 2002;35:3104-9.

16. Ray SS, Okamoto M, Yamada K, Ogami A, Ueda K. New polylactide/layered silicate nanocomposites. 5. Designing of materials with desired properties. Chem Mater. 2003;15:1456-62.

17. Sinha Ray S, Yamada K, Okamoto M, Ueda K. New polylactidelayered silicate nanocomposites. 2. Concurrent improvements of material properties, biodegradability and melt rheology. Polymer. 2003;44:857-66.

18. Zou H, Yi Ch, Wang L, Liu H, Xu W. Thermal degradation of poly(lactic acid) measured by thermogravimetry coupled to Fourier transform infrared spectroscopy. J Therm Anal Calorim. 2009;97:929-35.

19. Singh B, Sharma N. Mechanistic implications of plastic degradation. Polym Degrad Stab. 2008;93:561-84.

20. Sinha Ray S, Yamada K, Okamoto M, Ueda K. Control of biodegradability of polylactide via nanocomposite Technology. Macromol Mater Eng. 2003;288:203-8.

21. Solarski S, Ferreira M, Devaux E. Ageing of polylactide and polylactide nanocomposite filaments. Polym Degrad Stab. 2008;93:707-13.

22. Olewnik E, Richert J. Effect of the compatibilizing agent on the structure, mechanical and thermal properties of polylactide filled with modified and unmodified montmorillonite. Polym Compos. 2014;35:1330-7.

23. Li Y, Chen C, Li J, Sun XS. Synthesis and characterization of bionanocomposites of poly(lactic acid) and $\mathrm{TiO}_{2}$ nanowires by in situ polymerization. Polymer. 2011;52:2367-75.

24. Sosnowski S. Poly(L-lactide) microspheres with controlled crystallinity. Polymer. 2001;42:637-43.

25. Leszczyńska A, Njuguna J, Pielichowski K, Banerjee JR. Polymer/montmorillonite nanocomposites with improved thermal properties Part I. Factors influencing thermal stability and mechanisms of thermal stability improvement. Thermochim Act. 2007;453:75-96. 
26. Rabek JF. Photostabilization of polymers. Principles and application. London: Elsevier Applied Science Ltd., 1990.

27. Żenkiewicz M, Richert J. Permeability of polylactide nanocomposite films for water vapour, oxygen and carbon dioxide. Polym Test. 2008;27:835-40.

28. Tsuji H, Echizen Y, Nishimura Y. Photodegradation of biodegradable polyesters: a comprehensive study on poly(L-lactide) and poly(3-caprolactone). Polym Degrad Stab. 2006;91:1128-37.

29. Manich AM, Carilla J, Miguel RAL, Lucas JM, Franco FGF, Montero LA, Cayuela D. Thermal transitions of polylactide falsetwist textured multifilaments determined by DSC and TMA. J Therm Anal Calorim. 2010;99:723-31.

30. Bras AR, Viciosa MT, Dionísio M, Mano JF. Water effect in the thermal and molecular dynamics behaviour of poly(l-lactic acid). J Therm Anal Calorim. 2007;88:425-9.
31. Song P, Chen G, Wei Z, Zhang W, Liang J. Calorimetric analysis of the multiple melting behavior of melt-crystallized poly(L-lactic acid) with a low optical purity. J Therm Anal Calorim. 2013;111:1507-14.

32. Pluta M, Murariu M, Alexandre M, Galeski A, Dubois P. Polylactide compositions. The influence of ageing on the structure, thermal and viscoelastic properties of PLA/calcium sulfate composites. Polym Degrad Stab. 2008;93:925-31.

33. Frąszczak Z, Królikowski B. Selected properties of extruded bimodal high density polyethylene film. Polimery. 2009;54:132-7.

34. Mucha M, Białas S, Kaczmarek H. Effect of nanosilver on the photodegradation of poly(lactic acid). J Appl Polym Sci. 2014;131:40144. doi:10.1002/app.40144. 